\title{
REITER'S SYNDROME IN FATHER AND SON
}

Reiter's syndrome consists of a non-specific urethritis, conjunctivitis, polyarthritis, and a number of less constant features (Reiter, 1916).

The cause of the urethritis is unknown but it is commonly regarded by venereologists as an infective condition of venereal origin. Although a yearly average of more than 12,000 cases of non-specific urethritis have been reported to the Ministry of Health by Venereal Disease Clinics since 1951, only a small proportion ( 3 to 4 per cent.) develop the features of Reiter's syndrome.

It has been suggested that hereditary predisposition may perhaps explain why some patients with non-specific urethritis develop Reiter's syndrome (Laird, 1958). Some support for this theory is afforded by this paper which reports the occurrence of the syndrome in father and son.

\section{Case Reports}

Case 1, a schoolboy, aged 15, was admitted to another hospital in May, 1957, with a history of pain and swelling of the knees and ankles. An initial diagnosis of acute rheumatism was made and treatment was started with aspirin. He continued to run a pyrexia $\left(99-100^{\circ} \mathrm{F}\right.$.), but the erythrocyte sedimentation rate fell from $100 \mathrm{~mm}$. in 1 hour (Wintrobe) in June to $8 \mathrm{~mm}$. at the end of July. It then became clear that he had Reiter's syndrome as he developed a high fever and severe bilateral conjunctivitis. At this time he had had no urethral discharge and denied any form of sexual exposure. One week later pain and swelling developed in the left ankle, the first right metacarpophalangeal joint, and both knees, and the typical skin lesions of keratoderma blennorrhagica were noted on the soles of both feet (Figure, opposite).

Laboratory Investigations.- $\mathrm{Hb} 84$ per cent., blood film normal, white blood cells $5,500 / \mathrm{c} . \mathrm{mm}$.

Erythrocyte sedimentation rate $37 \mathrm{~mm}$. in 1 hour (Wintrobe).

$E$. coli were identified on culture of a urethral smear, but no pleuropneumonia-like organisms were demonstrated.

$X$ rays showed osteoporosis of the right wrist and thumb. Sub-periosteal new bone was present along the base of the proximal phalanx of the right thumb and the $-\vec{\omega}$ first metacarpal bone. Later views demonstrated con-in solidation of the periosteal new bone and a marginal 0 erosion on the lateral aspect of the first right metacarpal.

Progress.-The condition responded to fever therapy but not to salicylates. One year later (May, 1958) he $\vec{C}$ developed an acute recurrence with arthritis and kerato- $\mathbb{D}$ dermia, this time accompanied by non-specific urethritis, $\frac{\mathbb{D}}{\mathbb{D}}$ although again there was no history of venereal exposure. $\frac{\mathbb{}}{3}$ $X$ rays showed osteoporosis of the ends of both tibiae and

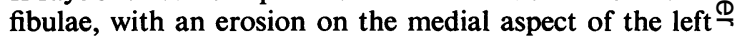
medial malleolus. Irregularities were noted at the sfe $\vec{\theta}$ of the ligamentous attachments of both tali and calcan

He responded again to fever therapy and was fit fer discharge in June, 1958. When seen in September, 1958, he complained of some tenderness of the soles of both feet and some low back pain, but was able to continue hiso apprenticeship as a joiner. He has since been lost to follow up.

Case 2, a 41-year-old salesman, father of Case 1, was윽 first seen in the Out-Patients' Department on February 27, 1958, complaining of episodes of pain and swelling of the ankles over the previous 2 years, and a recent, more severe attack involving the lumbar and cervical spine, both shoulders, and both wrists. These symptoms were? accompanied by a constitutional illness with loss of weight and general malaise and had persisted for severalweeks. There was a history of a post-coital urethralo discharge 5 years previously while serving in the armed $₹$ forces in India, and this had recurred several timeso during the previous 2 years. The patient claimed that investigations carried out in India at the time of theo initial discharge were negative for both syphilis and gonorrhoea. He had never had conjunctivitis or iritis. $\mathcal{N}$

Examination.-He looked pale and ill, with a sub- ${ }^{\circ}$ normal body temperature $\left(97 \cdot 4^{\circ}\right.$ F.). Movements of ${ }_{\mathrm{C}}$ the cervical spine were painful, so that he held his neck ${ }_{O}$ slightly flexed and rigid. Movements of lumbar spine were also limited by pain, but no deformity was present. Both ankles were swollen and painful, and effusions were present in both knee joints. The hands and wrists were ${ }^{-}$ clinically normal. 


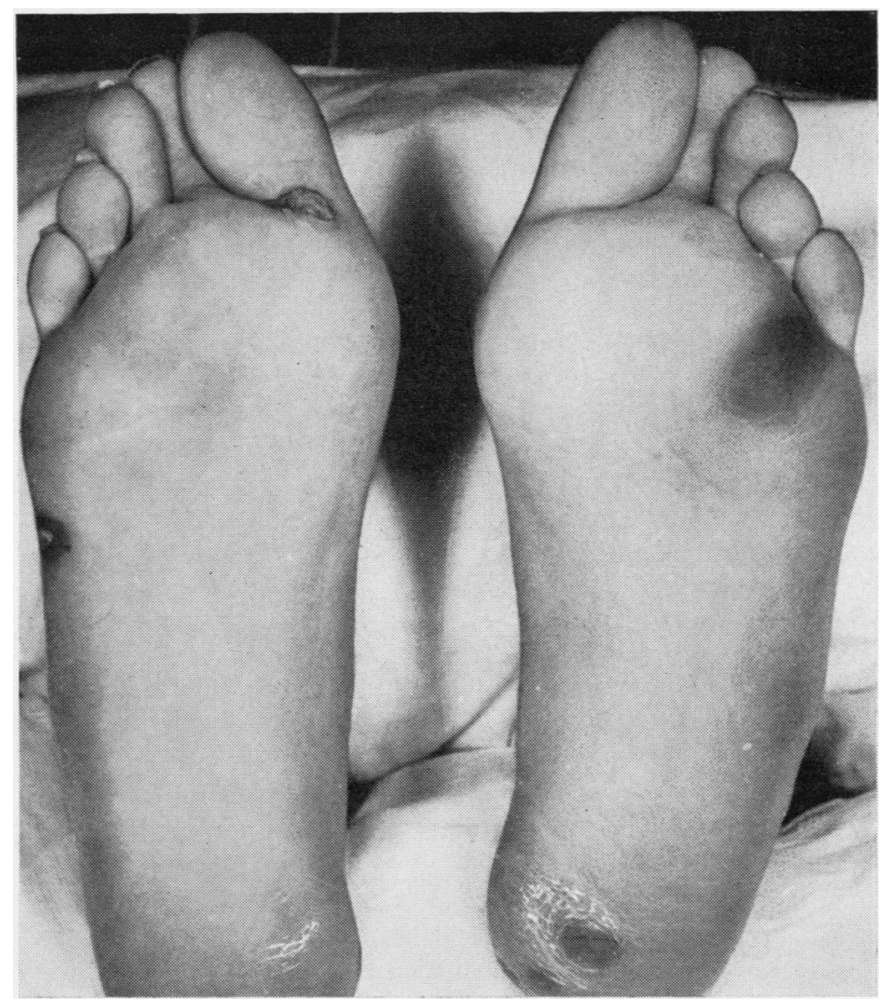

Laboratory Investigations. - Hb 72 per cent. (10.7 g./ $100 \mathrm{ml}$.), blood film normal, white blood cells 7,300/c.mm.

Erythrocyte sedimentation rate $55 \mathrm{~mm}$. in 1 hour (Wintrobe).

Mid-stream urine showed no albumin. Centrifuged deposit revealed very scanty white cells and culture was sterile. No pleuropneumonia-like organisms were demonstrated.

The Wassermann reaction and differential agglutination test were negative. Agglutination tests were negative for Brucella and Shigella organisms.

The serum uric acid was $4 \cdot 2 \mathrm{mg} . / 100 \mathrm{ml}$.

$X$ rays of the chest and sacro-iliac joints were normal.

On the plantar aspect of both calcanei there was a small area of cortical absorption at the insertion of the plantar aponeurosis.

Treatment.-Initial treatment with large doses of aspirin was unsuccessful and a course of fever therapy (T.A.B. intravenous injections) produced no significant improvement. Prednisone $10 \mathrm{mg}$. twice daily was then started, and this produced an immediate improvement in the pain, and increased the mobility of all the affected joints. The dose was reduced to $5 \mathrm{mg}$. three times daily, and on August 11, 1958, he was discharged home. Since then he has ignored requests to return to the OutPatients' Department for follow-up.

\section{Discussion}

The association of conjunctivitis, relapsing polyarthritis, non-specific urethritis, and keratoderma blennorrhagica leaves little doubt that Case 1 had Reiter's syndrome. It is likely that the father, Case 2, also suffered from the same condition. The pattern of joint involvement in both cases is typical of that seen in Reiter's syndrome. In fact, the diagnosis in the father was first suggested by the similarity of the joint involvement seen one year previously in the son. The urethritis occurring in the son was presumably not venereal in origin since he persistently denied sexual exposure, but it is possible that he contracted the infection from his father who had had a recurrent urethral discharge for a year or so before the onset of symptoms in the son.

Hereditary disposition is said to occur in a wide variety of rheumatic disorders. Rheumatoid arthritis occurs more often in the families of patients than in the families of matched controls (Hersh, Stecher, Solomon, Wolpaw, and Hauser, 1950). West (1949) concluded that the familial incidence of ankylosing spondylitis was greater than might be 
expected on the grounds of chance alone. The familial incidence of gout is well established (Stecher, Hersh, and Solomon, 1949), and a familial tendency has been claimed in rheumatic fever (Stevenson and Cheeseman, 1956).

Some evidence exists that there may also be a familial predisposition to Reiter's syndrome. Csonka (1958) reported the condition occurring in two brothers, and Morton (1958) in first cousins. A full-scale investigation of the families of patients with Reiter's syndrome has not been reported. The two cases described in this paper lend some support to the theory that a familio-hereditary factor operates.

An interesting analogy between rheumatic fever and Reiter's syndrome has been proposed by Laird (1958), who postulated that the polyarthritis of Reiter's syndrome might arise from sensitization of the tissues following infection in the genitourinary or intestinal tracts, much as acute rheumatism follows a streptococcal sore throat. Just as only a small proportion of patients with streptococcal sore throats develop acute rheumatism, only a small proportion of patients with non-specific urethritis develop Reiter's syndrome. Hereditary predisposition may be one of the factors determining which patients develop the polyarthritis, conjunctivitis, and the less common features of the syndrome.

\section{Summary}

It has been suggested that hereditary predisposition may perhaps explain why some patients with non-specific urethritis develop Reiter's syndrome. Some support for this theory is afforded by this paper which reports the occurrence of the syndrome in father and son.

I wish to express my thanks to Professor C. Bruce Perry for permission to publish details of both cases? and for his help with the manuscript.

\section{REFERENCES}

Csonka, G. W. (1958). Brit. med. J., 1, 1088. Hersh, A. H., Stecher, R. M., Solomon, W. M., Wolpawฏ R., and Hauser, H. (1950). Amer. J. hum Genet., 2, 391.

Laird, S. M. (1958). Brit. J. vener. Dis., 34, 137.

Morton, R. S. (1958). Ibid., 34, 50.

Reiter, H. (1916). Dtsch. med. Wschr., 42, 1535.

Stecher, R. M., Hersh, A. H., and Solomon, W. Mọ (1949). Ann. intern. Med., 31, 595.

Stevenson, A. C., and Cheeseman, E. A. (1956). Ann $\vec{\omega}$ hum. Gentt., 21, 139.

West, H. F. (1949). Ann. rheum. Dis., 8, 143.

Syndrome de Reiter chez père et fils

\section{RÉSUMÉ}

Il existe une hypothèse selon laquelle une prédispositior héréditaire expliquerait le fait que certains malades atteints d'une uréthrite non-spécifique développent lẹ syndrome de Reiter. Cet article rapportant l'occer-rence de ce syndrome chez père et fils vient à l'apêngh de cette théorie.

\section{Sindrome de Reiter en padre e hijo} SUMARIO

Se había sugerido que una predisposición hereditariao pudiera quizás explicar por qué ciertos enfermos corp uretritis non-específica desarrollan el síndrome de Reiter $\overrightarrow{\vec{B}}$ En este artículo, en apoyo de la dicha teoría, se relatas la ocurrencia de este síndrome en padre e hijo. 